\title{
Trends in CD4 counts in HIV-infected patients with HIV viral load monitoring while on combination antiretroviral treatment: results from The TREAT Asia HIV Observational Database
}

\author{
Jialun Zhou ${ }^{1 *}$, Thira Sirisanthana², Sasisopin Kiertiburanakul ${ }^{3}$, Yi-Ming A Chen ${ }^{4}$, Ning Han ${ }^{5}$, Poh_Lian Lim ${ }^{6}$ \\ Nagalingeswaran Kumarasamy ${ }^{7}$, Jun Yong Choi ${ }^{8}$, Tuti Parwati Merati ${ }^{9}$, Evy Yunihastuti ${ }^{10}$, Shinichi Oka ${ }^{11}$, \\ Adeeba Kamarulzaman ${ }^{12}$, Praphan Phanuphak ${ }^{13}$, Christopher KC Lee ${ }^{14}$, Patrick CK Li ${ }^{15}$, Sanjay Pujari ${ }^{16}$, \\ Vanthanak Saphonn ${ }^{17}$, Matthew G Law ${ }^{1}$
}

\begin{abstract}
Background: The aim of this study was to examine the relationship between trends in CD4 counts (slope) and HIV viral load (VL) after initiation of combination antiretroviral treatment (CART) in Asian patients in The TREAT Asia HIV Observational Database (TAHOD).

Methods: Treatment-naive HIV-infected patients who started CART with three or more and had three or more CD4 count and HIV VL tests were included. CD4 count slopes were expressed as changes of cells per microliter per year. Predictors of CD4 count slopes from 6 months after initiation were assessed by random-effects linear regression models.

Results: A total of 1676 patients (74\% male) were included. The median time on cART was 4.2 years (IQR 2.5-5.8 years). In the final model, CD4 count slope was associated with age, concurrent HIV VL and CD4 count, disease stage, hepatitis B or C co-infection, and time since CART initiation. CD4 count continues to increase with HIV VL up to 20000 copies/mL during 6-12 months after CART initiation. However, the HIV VL has to be controlled below 5 000, 4000 and 500 copies/mL for the CD4 count slope to remain above 20 cells/microliter per year during 12-18, 18-24, and beyond 24 months after CART initiation.

Conclusions: After CART initiation, CD4 counts continued to increase even when the concurrent HIV VL was detectable. However, HIV VL needed to be controlled at a lower level to maintain a positive CD4 count slope when CART continues. The effect on long-term outcomes through the possible development of HIV drug resistance remains uncertain.
\end{abstract}

\section{Background}

Studies show that latent infection of $\mathrm{CD} 4$ cells provides a mechanism for lifelong persistence of HIV-1, even in patients on effective anti-retroviral therapy [1]. To suppress viral replication so that the VL is below the level of detection with standard assays is thus one of the aims at the start of antiretroviral treatment. Maximal and

\footnotetext{
* Correspondence: jzhou@nchecr.unsw.edu.au

${ }^{1}$ National Centre in HIV Epidemiology and Clinical Research, The University of New South Wales, Sydney, Australia

Full list of author information is available at the end of the article
}

durable suppression of HIV VL prevents or delays development of drug resistant mutations, preserves CD4 cells, and eventually results in better clinical outcomes. According to the US guidelines, if HIV VL suppression is not achieved, it is necessary to change to a new regimen, a second or third line regimen, with at least two active drugs [2].

HIV-infected patients in most developing countries have limited second and third line antiretroviral treatment options [3]. In many countries in Asia, second-line combination antiretroviral treatment (cART) is not 
widely accessible [4-6]. There remains some uncertainty about the short-term risks to patients receiving first line cART, in particular how their immune status might deteriorate if they persist with a virologically failing regimen. The Pursuing Later Treatment Options (PLATO) collaboration [7] reported that in patients experiencing triple class failure, treatment regimens that maintain the VL below 10000 copies/mL or at least provide 1.5 $\log 10$ copies/mL suppression below the off-treatment value do not seem to be associated with appreciable CD4-cell-count decline. More recently, Mocroft et al [8] also reported that CD4 did not significantly decrease even HIV VL exceeded 10000 copies $/ \mathrm{mL}$ in patients treated with regimen containing a boosted protease inhibitor. The issue of when to switch from first line regimens may therefore be difficult, especially for patients with modest, stable HIV VL who are clinically doing well $[5,9]$.

The aims of this study were to examine the relationship between trends in CD4 count and VL after initiation of combination antiretroviral treatment in HIV-infected Asian patients, using data from The TREAT Asia HIV Observational Database (TAHOD).

\section{Methods}

Established in 2003, TAHOD is a collaborative observational cohort study involving 18 sites in the Asia-Pacific region (See acknowledgement). Detailed methods are published elsewhere [10]. Briefly, each site recruited approximately 200-300 HIV-infected patients, including both patients on or not initiating antiretroviral treatment. Recruitment was based on a consecutive series of patients regularly attending a given site from a particular start-up time. Ethical approval for the study was obtained from the University of New South Wales Ethics Committee and respective local ethics committee.

The following data were collected: patient demographics and baseline data, CD4 and CD8 count, HIV VL level, prior and new AIDS defining illness (ADI), date and cause of death, prior and current prescribed HAART, and reason for treatment change. Data are collected according to a common protocol. Upon recruitment, all available data prior to entry to TAHOD (considered as retrospective data) are extracted from patient case notes. Prospective data are updated sixmonthly at each clinic and transferred to data management centre for aggregation and analyses. TAHOD sites are encouraged to contact patients who were not seen in the clinics in the previous 12 months.

TAHOD patients were included in this analysis if they were treatment naïve and initiated with triple or more combination antiretroviral treatment, and had three or more concurrent CD4 and HIV VL test pairs (within 28 days if not tested on the same day) during follow-up.
Both retrospective and prospective data were included in the analysis.

Trends in CD4 count (slope) was calculated by linear regression with the values at time $\mathrm{T}$, before $\mathrm{T}$, and after $\mathrm{T}$, and was expressed as changes of cells per microliter $(\mu \mathrm{L})$ per year. The HIV VL was related to the CD4 count slope at time T. Previous studies reported a two-phase CD4 count response, demonstrated as a rapid increase (a high CD4 count slope) in the first several months after treatment initiation and followed by slower increase (a smaller slope compared to the initial several months) [11-14]. Preliminary analyses in eligible TAHOD patients showed that the mean CD4 count slope was significantly higher in the first 6 months after cART initiation than in the period afterwards ( 179 vs. 44 cells $/ \mu \mathrm{L}$ per year, $\mathrm{p}<0.001)$. The CD4 slopes were therefore calculated from CD4 counts measured 6 months after cART initiation.

Predictors of the CD4 slope at time $\mathrm{T}$ was assessed by random-effect linear regression models which take account of within and between patient variability. Covariates included sex, age (per 10 years), disease stage (CDC category A, tuberculosis with or without other AIDS defining illness, other non-tuberculosis AIDS defining illness), hepatitis coinfection (hepatitis B or C antibody positive), haemoglobin level, time since cART initiation, initial cART regimen non-nucleoside/nucleotide reverse transcriptase inhibitor (NNRTI)-based, nonboosted PI, or boosted PI, and treatment containing abacavir. Disease stage, CD4 count and HIV VL were fitted in the model as time-dependent variable. We did not include CD4 count and HIV VL at baseline for the following three reasons: first, a large proportion of patients did not have the tests at treatment initiation (approximately $25 \%$ of patients had no CD4 count and 45\% HIV VL, Table 1); second, the model aimed to help clinicians in this region to assess the status of immune system with the clinical information at hand (e.g., age, hepatitis status, current CD4 count, time since treatment initiation, etc) where the baseline information on CD4 count and HIV VL may not be readily available; and third, when we included baseline CD4 and HIV VL in a sensitivity analyses based on the subset of patients with baseline data available, the results remained comparable with the model without the baseline CD4 count and HIV VL. The multivariate models were built using a forward-step approach, the final model included covariates that remained significant at the 0.20 level. Nonsignificant variables were also presented and adjusted for in the final multivariate models.

To take into consideration of the treatment interruption and switch, the following sensitivity analyses were performed: 1 . restricting the records measured during initial NNRTI-based regimen; 2. excluding the records 
Table 1 Patient characteristics at baseline in patients selected in the analysis and patients starting 3 or more cART in TAHOD

\begin{tabular}{|c|c|c|c|c|c|}
\hline & In analysis & In TAHOD & & In analysis & In TAHOD \\
\hline Total patients & 1676 & 4056 & \multicolumn{3}{|c|}{ Haemoglobin $(\mathrm{g} / \mathrm{dL})$ at CART initiation } \\
\hline Age (year) at CART initiation & & & Median (IQR) & $14.0(12.6,15.2)$ & $12.3(10.8,14.2)$ \\
\hline Median (IQR) & $36(30,42)$ & $35(30,41)$ & $<10 \mathrm{~g} / \mathrm{dL}$ & $27(2 \%)$ & $418(16 \%)$ \\
\hline$<=30$ & $437(26 \%)$ & $1188(29 \%)$ & $10+g / d L$ & $1248(98 \%)$ & $2250(84 \%)$ \\
\hline $31 \sim 40$ & $748(45 \%)$ & $1814(45 \%)$ & Not tested & 221 & 1388 \\
\hline \multirow[t]{2}{*}{41 or more } & $491(29 \%)$ & $1054(26 \%)$ & \multicolumn{3}{|c|}{ CD4 count (cells/ $\mu \mathrm{L}$ ) at cART initiation } \\
\hline & & & Median (IQR) & $140(42,230)$ & $112(37,209)$ \\
\hline Gender & & & $<=50$ & $350(28 \%)$ & $990(31 \%)$ \\
\hline Male & $1238(74 \%)$ & $2875(71 \%)$ & $51-100$ & $155(12 \%)$ & $508(16 \%)$ \\
\hline Female & $438(26 \%)$ & $1177(29 \%)$ & $101-200$ & $328(26 \%)$ & $815(26 \%)$ \\
\hline \multirow[t]{2}{*}{ Transgender } & $0(0 \%)$ & $4(<1 \%)$ & $201-300$ & $261(21 \%)$ & $551(17 \%)$ \\
\hline & & & 301 or more & $161(13 \%)$ & $311(10 \%)$ \\
\hline \multicolumn{3}{|c|}{ CDC clinical classification for HIV infection at CART initiation } & Not tested & 421 & 881 \\
\hline Stage A & $980(58 \%)$ & $1984(50 \%)$ & \multicolumn{3}{|c|}{ HIV viral load (copies/ml) at cART initiation } \\
\hline Stage B & $101(6 \%)$ & $407(10 \%)$ & Median $\log 10(\mathrm{QQR})$ & $4.93(4.22,5.52)$ & $4.94(4.32,5.51)$ \\
\hline \multirow[t]{2}{*}{ Stage C } & $595(36 \%)$ & $1665(41 \%)$ & $<500$ & $101(11 \%)$ & $126(9 \%)$ \\
\hline & & & $501-10,000$ & $80(9 \%)$ & $124(9 \%)$ \\
\hline Hepatitis B or C coinfection & & & $10,001-50,000$ & $173(19 \%)$ & $280(20 \%)$ \\
\hline No & $1468(88 \%)$ & 3495 (86\%) & 50,001 or more & 555 (61\%) & 885 (62\%) \\
\hline Yes & $208(12 \%)$ & $566(14 \%)$ & Not tested & 767 & 2641 \\
\hline
\end{tabular}

measured when patients were off-treatment for more than 30 days for various reasons. Finally, sensitivity analysis was also performed by restricting the records in patients contributing at least 4 or more concurrent CD4 and HIV VL tests.

Data management and statistical analyses were performed using SAS for Windows (SAS Institute Inc., Cary, NC, USA), and Stata (StataCorp, STATA 10.1 for Windows, College Station, Texas 77845 USA).

\section{Results}

There were 4699 patients with data collected in TAHOD as at September 2009. Approximately $75 \%$ of patients had a clinic visit in the 12 months before September 2009 , and 214 patients died since entry to TAHOD (mortality 1.36 per 100 person years). Among the 4699 TAHOD patients, 612 were not currently receiving antiretroviral treatment, 31 were receiving mono or dual therapy, and 4056 had initiated cART with three or more drugs. 1676 naïve patients initiated cART, and had three or more concurrent CD4 and HIV VL data pairs available beyond 6 months after cART initiation.

Table 1 shows the patient characteristics at cART initiation in patients included in the analysis and in all TAHOD patients who initiated cART with three or more drugs. The characteristics of the patients included in the analysis are generally comparable to those of the whole TAHOD patients, except that the patients included were less likely to be anemic.
At cART initiation, the median age of the patients included in the analysis was 36 years (interquartile range, IQR, 30-42), median CD4 count 140 cells $/ \mu \mathrm{L}$ (IQR 42-230), median HIV VL $5.00 \log 10$ copies/mL (IQR 4.33-5.56), 12\% had hepatitis B or C co-infection, and $36 \%$ were diagnosed with an AIDS defining illness (ADI). The median time on cART was 4.2 years (IQR 2.5 - 5.8). The median time between each CD4 and HIV VL tests was 165 days (IQR 106 - 223). The initial cART was predominantly an NNRTI-based regimen (63\% of 1676 patients in the analysis, with either nevirapine or efavirenz, plus two NRTI drugs, mostly stavudine or zidovudine, plus lamivudine). Approximately $15 \%$ of the patients started a non-boosted PI (mostly indinavir, nelfinavir or atanazavir) regimen with two NRTI drugs and 20\% started with a ritonavir-boosted PI (mostly lopinavir, atanazavir or saquinavir). The annual rate of a drug class change or change of at least two or more drugs was approximately $20 \%$. After cART initiation, viral logical suppression (HIV VL $<400$ copies/ $\mathrm{mL}$ ) was achieved in $83 \%$ of patients at 6 month and $82 \%$ in 12 months.

Table 2 shows the random-effect linear regression analysis of the CD4 count slope. Concurrent haemoglobin level, initial cART containing NNRTI or boosted PI were not significantly associated with the study endpoint in both univariate and multivariate analyses. Initial cART containing abacavir was significant in the univariate analysis. In the final multivariate model, CD4 count 
Table 2 Random-effect linear regression analyses of trend of CD4 count (slope, cells/ $\mu \mathrm{L}$ per year)

\begin{tabular}{|c|c|c|c|c|c|c|}
\hline & \multicolumn{3}{|c|}{ Univariate } & \multicolumn{3}{|c|}{ Multivariate ${ }^{* *}$} \\
\hline & Difference* & $(95 \% \mathrm{Cl})$ & $\mathrm{p}$ value & Difference* & $(95 \% \mathrm{Cl})$ & $\mathrm{p}$ value \\
\hline \multicolumn{7}{|l|}{ Sex } \\
\hline Male* & 0.0 & & & 0.0 & & \\
\hline Female & 9.5 & $(0.1,18.9)$ & 0.047 & 7.8 & $(-1.5,17.2)$ & 0.099 \\
\hline \multicolumn{7}{|l|}{ Current age } \\
\hline per 10 years older & -6.5 & $(-10.3,-2.7)$ & 0.001 & -4.8 & $(-8.6,-1.0)$ & 0.013 \\
\hline \multicolumn{7}{|l|}{$\underline{\text { Disease stage }}$} \\
\hline CDC Category $A^{*}$ & 0.0 & & & 0.0 & & \\
\hline TB with or without other ADI & 24.4 & $(13.7,35.1)$ & $<0.001$ & 26.3 & $(15.6,37.0)$ & $<0.001$ \\
\hline Non-TB ADI(s) & 3.7 & $(-5.6,13.0)$ & 0.433 & 12.0 & $(2.5,21.4)$ & 0.013 \\
\hline \multicolumn{7}{|l|}{$\underline{\text { Haemglobin level }}$} \\
\hline per $1 \mathrm{~g} / \mathrm{dL}$ higher & 0.0 & $(-0.0,0.1)$ & 0.661 & 0.0 & $(-0.0,0.1)$ & 0.689 \\
\hline \multicolumn{7}{|l|}{ Concurrent CD4 count } \\
\hline Per 100 cells/uL higher & 1.3 & $(-0.3,3.0)$ & 0.116 & 1.9 & $(0.2,3.7)$ & 0.033 \\
\hline \multicolumn{7}{|l|}{$\underline{\text { Concurrent viral load }}$} \\
\hline per log10 copies/mL higher & -40.9 & $(-48.7,-33.2)$ & $<0.001$ & -40.5 & $(-48.4,-32.6)$ & $<0.001$ \\
\hline \multicolumn{7}{|l|}{$\underline{\text { Hepatitis B or C coinfection }}$} \\
\hline $\mathrm{No}^{*}$ & 0 & & & 0 & & \\
\hline Yes & -19.1 & $(-31.1,-7.0)$ & 0.002 & -17.7 & $(-29.7,-5.7)$ & 0.004 \\
\hline \multicolumn{7}{|l|}{ Time since CART initiation } \\
\hline$>6$ to $\leq 12$ months* & 0.0 & & & 0.0 & & \\
\hline$>12$ to $\leq 18$ months & -21.3 & $(-37.7,-5.0)$ & 0.011 & -21.5 & $(-37.8,-5.2)$ & 0.010 \\
\hline$>18$ to $\leq 24$ months & -23.1 & $(-39.3,-7.0)$ & 0.005 & -25.8 & $(-42.0,-9.7)$ & 0.002 \\
\hline$>24$ or more months & -58.0 & $(-70.3,-45.7)$ & $<0.001$ & -59.1 & $(-71.7,-46.5)$ & $<0.001$ \\
\hline \multicolumn{7}{|l|}{ Initial CART containing NNRTI } \\
\hline $\mathrm{No}^{*}$ & 0.0 & & & 0.0 & & \\
\hline Yes & 6.4 & $(-1.4,14.1)$ & 0.106 & -1.3 & $(-9.2,6.6)$ & 0.749 \\
\hline \multicolumn{7}{|l|}{ Initial CART containing boosted PI } \\
\hline $\mathrm{No}^{*}$ & 0.0 & & & 0.0 & & \\
\hline Yes & -0.8 & $(-10.5,9.0)$ & 0.880 & -3.4 & $(-13.2,6.3)$ & 0.493 \\
\hline \multicolumn{7}{|l|}{$\underline{\text { Initial CART containing abacavir }}$} \\
\hline $\mathrm{No}^{*}$ & 0.0 & & & & & \\
\hline Yes & -12.9 & $(-25.8,0.0)$ & 0.050 & -5.6 & $(-18.5,7.3)$ & 0.397 \\
\hline
\end{tabular}

* Difference were compared with the first category of each categorical variable.

** Constant term for multivariate model: $205.5(174.4,236.6)$ cells per $\mu \mathrm{L}$ per year.

slope was associated with age $(-4.8$ cells/ $\mu \mathrm{L}$ per year per 10 -year age increase, $\mathrm{p}=0.013)$, concurrent HIV VL $(-40.5$ per $1 \log 10$ copies $/ \mathrm{mL}$ VL increase, $\mathrm{p}<0.001)$, concurrent CD4 count ( +1.9 per 100 cells/ $\mu \mathrm{L}$ increase), disease stage (compared to CDC category A illnesses: +26.3 if diagnosed with tuberculosis [TB] with or without other ADI, $\mathrm{p}<0.001 ;+12.0$ if diagnosed with non-TB $\mathrm{ADI}, \mathrm{p}=0.013)$, hepatitis $\mathrm{B}$ or $\mathrm{C}$ co-infection $(-17.7$ if coinfected, $\mathrm{p}=0.004)$, and time since cART initiation (compared to CD4 slope during 6-12 months: -21.5 during 12-18 months, $\mathrm{p}=0.010$; -25.8 during $18-24$ months, $\mathrm{p}=0.002 ;-59.1$ at 24 months or later, $\mathrm{p}<0.001$ ).

In Figure 1 we gave the formula obtained from Table 2 and an example to estimate the CD4 slope. The formula needs the following information: current age, concurrent
CD4 count and HIV VL, hepatitis coinfection, disease stage, and time since cART initiation.

The models shows that, after cART initiation, mean CD4 counts continued to increase even when the concurrent HIV VL was detectable. In addition, the model also shows that to maintain a positive CD4 count slope, the HIV VL needed to be suppressed to a lower level in later periods of cART. To illustrate, the estimated CD4 slopes from the model in two patients with specific baseline characteristics are shown in Table 3 and in Figure 2. The bold cells are when the estimated CD4 count slope falls between -20 and +20 cell $/ \mu \mathrm{L}$ per year, which we considered as indicative of borderline CD4 count decreases. In the case of the first patient (aged 30 years, no hepatitis coinfection and AIDS defining 


\section{Information required: \\ AGE: Current age (years) \\ CD4: Concurrent CD4 count (cells/ $\mu \mathrm{L}$ ) \\ VL: Concurrent HIV viral load (copies $/ \mathrm{mL}$ )}

HEPATITIS: Hepatitis coinfection

STAGE: Disease stage

$$
\begin{aligned}
& 1=\text { No } \\
& 2=\text { Yes }
\end{aligned}
$$

$$
\begin{aligned}
& 1=\text { CDC category } A \\
& 2=\text { TB with or without other ADI } \\
& 3=\text { Non-TB ADI }
\end{aligned}
$$

TIME: Time since initiation of combination antiretroviral treatment
$1:>6$ to $\leq 12$ months
2: $>12$ to $\leq 18$ months
3: $>18$ to $\leq 24$ months
4: $>24$ or more months

$$
\begin{gathered}
\text { CD4 slope (cells/ } \mu \text { L per year) } \\
=205.5+(-4.8) \times(\text { AGE } / 10)+(1.9) \times(\mathbf{C D} 4 / 100)+(-40.5) \times(\log 10(\mathrm{VL})) \\
+\left\{\begin{array}{r}
0 \text { if TIME }=1 \\
-17.7 \text { if HEPATITIS }=2
\end{array}\right\}+\left\{\begin{array}{r}
0 \text { if STAGE }=1 \\
26.3 \text { if STAGE }=2 \\
12.0 \text { if STAGE }=3
\end{array}\right\}+\left\{\begin{array}{r}
-21.5 \text { if TIME }=2 \\
-25.8 \text { if TIME }=3 \\
-59.1 \text { if TIME }=4
\end{array}\right\}
\end{gathered}
$$

For example, if a patient is 30 years old (i.e. AGE $=30$ ), concurrent CD4 250 cells $/ \mu \mathrm{L}$ (i.e. CD4 = 250), HIV VL 5000 copies/mL (i.e. VL=5000), no coinfection (i.e. HEPATITIS = 1), no ADI (i.e. STAGE = 1), and started CART 15 months ago (i.e. TIME = 2), the estimated CD4 slope would then be:

$$
\begin{aligned}
& 205.5+(-4.8) \times(30 / 10)+(1.9) \times(250 / 100)+(-40.5) \times(\log 10(5000)) \\
& +(0)+(0)+(-21.5)=24.5 \text { cells/ } / \mathrm{L} \text { per year }
\end{aligned}
$$

Figure 1 Estimating CD4 count slope.

illness, and concurrent CD4 count 200 cells/ $\mu \mathrm{L}$ ), the CD4 count continues to increase with HIV VL up to 20000 copies/mL during 6-12 months after cART initiation. However, the HIV VL has to be controlled below 5 000, 4 000 and 500 copies/mL for the CD4 count slope to remain on a safe level above 20 cells/ $\mu \mathrm{L} /$ year during 12-18, 18-24, and beyond 24 months after cART initiation.

Hepatitis co-infection had a significant effect on the CD4 count slope. In one scenario, shown in Table 3 of a 30-year old patient with concurrent CD4 count 200 cells $/ \mu \mathrm{L}$, no AIDS defining illness and no hepatitis coinfection, CD4 counts continues to increase with HIV VL up to 5000 copies/mL during 12-18 months after cART. If this patient was hepatitis co-infected, the CD4 count starts to fall when the HIV VL increases up to 3000 copies/mL.

The analyses were repeated in three subgroups as sensitivity analysis (Table 4). The results are comparable to the final model.

\section{Discussion}

In a subset of TAHOD patients who were treatment naïve and initiated with three or more combination antiretroviral treatment and had concurrent CD4 count and 
Table 3 Estimated CD4 slope (cells/ $\mu \mathrm{L} /$ year) by duration of treatment and HIV VL.

\begin{tabular}{|c|c|c|c|c|c|c|c|c|c|c|c|c|c|}
\hline \multirow{2}{*}{$\begin{array}{l}\text { Month since cART } \\
\text { initiation }\end{array}$} & \multicolumn{13}{|c|}{ HIV VL level (copies/mL) } \\
\hline & 500 & 1000 & 2000 & 3000 & 4000 & 5000 & 10000 & 20000 & 30000 & 40000 & 50000 & 100000 & 150000 \\
\hline & \multicolumn{13}{|c|}{ Patient 1, 30 years old, no hepatitis coinfection, no AIDS defining illness, and current CD4 200 cells per $\mu \mathrm{L}$} \\
\hline $6-12$ & 85.6 & 73.4 & 61.2 & 54.1 & 49.0 & 45.1 & 32.9 & 20.7 & 13.6 & 8.5 & 4.6 & -7.6 & -14.7 \\
\hline $12-18$ & 64.1 & 51.9 & 39.7 & 32.6 & 27.5 & 23.6 & 11.4 & -0.8 & -7.9 & -13.0 & -16.9 & -29.1 & -36.2 \\
\hline $18-24$ & 59.8 & 47.6 & 35.4 & 28.3 & 23.2 & 19.3 & 7.1 & -5.1 & -12.2 & -17.3 & -21.2 & -33.4 & -40.5 \\
\hline \multirow[t]{2}{*}{$24+$} & 26.5 & 14.3 & 2.1 & -5.0 & -10.1 & -14.0 & -26.2 & -38.4 & -45.5 & -50.6 & -54.5 & -66.7 & -73.8 \\
\hline & \multicolumn{13}{|c|}{ Patient 2, 30 years old, coinfected with hepatitis, no AIDS defining illness, and current CD4 200 cells per $\mu \mathrm{L}$} \\
\hline $6-12$ & 67.9 & 55.7 & 43.5 & 36.4 & 31.3 & 27.4 & 15.2 & 3.0 & -4.1 & -9.2 & -13.1 & -25.3 & -32.4 \\
\hline $12-18$ & 46.4 & 34.2 & 22.0 & 14.9 & 9.8 & 5.9 & -6.3 & -18.5 & -25.6 & -30.7 & -34.6 & -46.8 & -53.9 \\
\hline $18-24$ & 42.1 & 29.9 & 17.7 & 10.6 & 5.5 & 1.6 & -10.6 & -22.8 & -29.9 & -35.0 & -38.9 & -51.1 & -58.2 \\
\hline $24+$ & 8.8 & -3.4 & -15.6 & -22.7 & -27.8 & -31.7 & -43.9 & -56.1 & -63.2 & -68.3 & -72.2 & -84.4 & -91.5 \\
\hline
\end{tabular}

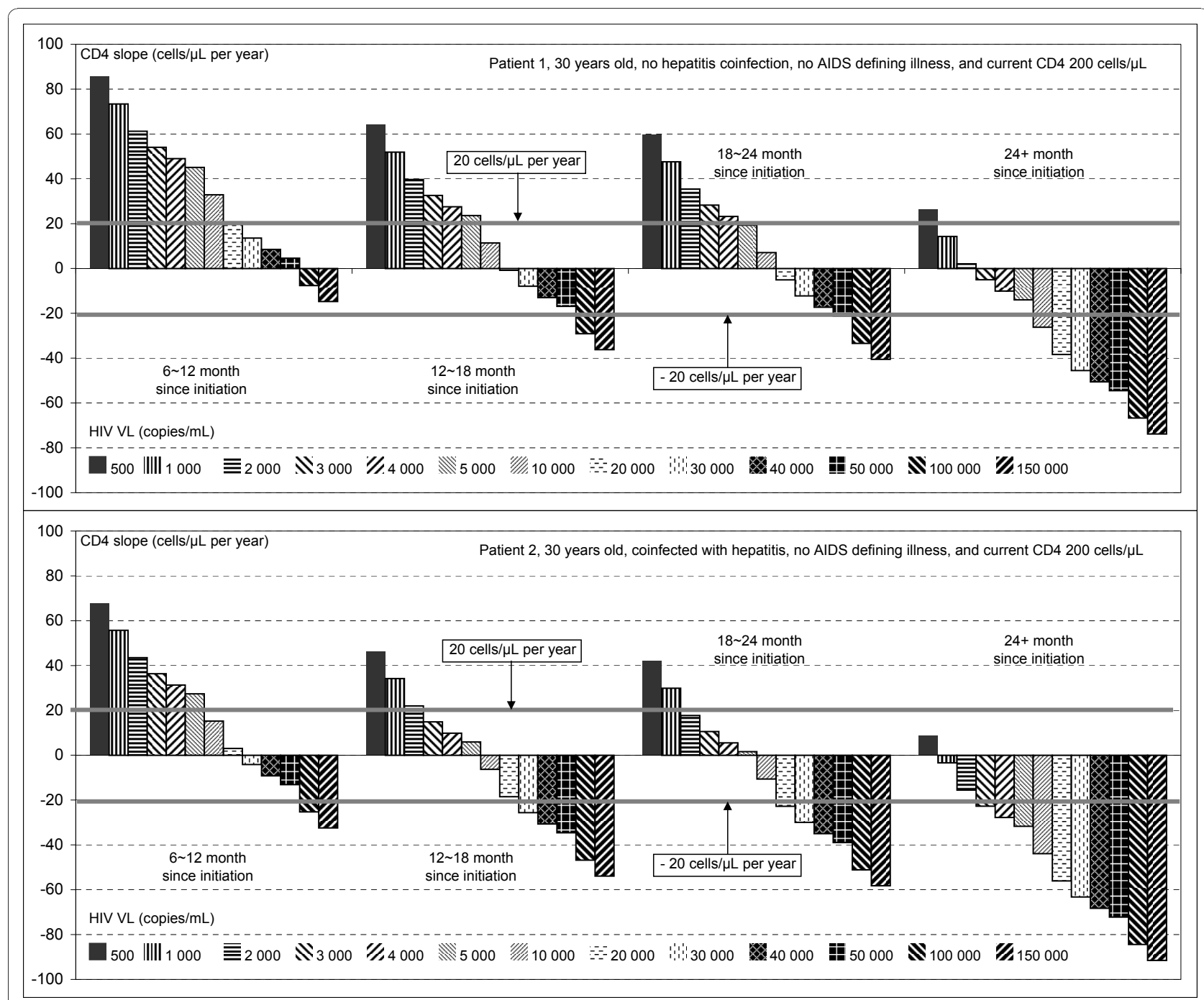

Figure 2 Estimated CD4 slope (cells/ $\mu \mathrm{L} /$ year) by duration of treatment and HIV VL. 
Table 4 Sensitivity analyses of the CD4 count slope.

\begin{tabular}{|c|c|c|c|c|c|c|c|c|}
\hline & \multirow{4}{*}{ Difference* $^{*}$} & \multirow{2}{*}{$\begin{array}{c}\text { Final model } \\
(95 \% \mathrm{Cl})\end{array}$} & \multicolumn{2}{|c|}{$\begin{array}{l}\text { Initial treatment, before } \\
\text { any class change or stop } \\
\text { for more than } 30 \text { days }\end{array}$} & \multicolumn{2}{|c|}{$\begin{array}{r}\text { Initial NNRTI-based } \\
\text { regimen, before change } \\
\text { or stop for more than } 30 \\
\text { days }\end{array}$} & \multicolumn{2}{|c|}{$\begin{array}{r}\text { Including patients with } 4 \\
\text { or more CD4 slopes } \\
\text { endpoints }\end{array}$} \\
\hline & & & Difference* & $(95 \% \mathrm{Cl})$ & Difference* & $(95 \% \mathrm{Cl})$ & Difference* & (95\% Cl) \\
\hline & & $\begin{array}{r}\text { Observations } \\
=10899\end{array}$ & & $\begin{array}{r}\text { Observations } \\
=6697\end{array}$ & & $\begin{array}{r}\text { Observations } \\
=4058\end{array}$ & & $\begin{array}{r}\text { Observations } \\
=9826\end{array}$ \\
\hline & & $\begin{array}{r}\text { Patients = } \\
1676\end{array}$ & & $\begin{array}{r}\text { Patients = } \\
1353\end{array}$ & & $\begin{array}{r}\text { Patients }= \\
863\end{array}$ & & $\begin{array}{r}\text { Patients }= \\
1079\end{array}$ \\
\hline \multicolumn{9}{|l|}{$\begin{array}{l}\text { Current age, per } 10 \text { yrs } \\
\text { older }\end{array}$} \\
\hline per unit & -4.8 & $(-8.6,-1.0)$ & -4.0 & $(-9.0,1.0)$ & -2.4 & $(-9.2,4.4)$ & -4.3 & $(-8.4,-0.2)$ \\
\hline \multicolumn{9}{|l|}{$\frac{\text { Concurrent viral load, per }}{\text { log10 copies per } \mathrm{mL}}$} \\
\hline per unit & -40.5 & $(-48.4,-32.6)$ & -43.4 & $(-58.5,-28.4)$ & -45.1 & $(-68.0,-22.2)$ & -39.5 & $(-48.1,-30.9)$ \\
\hline \multicolumn{9}{|l|}{$\begin{array}{l}\text { Concurrent CD4 per } 100 \\
\text { per } \mu \mathrm{L} \text { higher }\end{array}$} \\
\hline per unit & 1.9 & $(0.2,3.7)$ & 3.4 & $(1.0,5.7)$ & 4.1 & $(0.9,7.3)$ & 1.9 & $(0.0,3.8)$ \\
\hline \multicolumn{9}{|l|}{ Disease stage } \\
\hline CDC Category A* & 0.0 & & 0.0 & & 0.0 & & 0.0 & \\
\hline TB and/or other ADI & 26.3 & $(15.6,37.0)$ & 29.9 & $(16.1,43.7)$ & 29.9 & $(13.9,45.9)$ & 26.4 & $(14.6,38.1)$ \\
\hline Non-TB ADI(s) & 12.0 & $(2.5,21.4)$ & 16.4 & $(3.4,29.4)$ & 16.3 & $(-1.2,33.9)$ & 11.2 & $(0.9,21.6)$ \\
\hline \multicolumn{9}{|l|}{$\frac{\text { Hepatitis B or C }}{\text { coinfection }}$} \\
\hline $\mathrm{No}^{*}$ & 0.0 & & 0.0 & & 0.0 & & 0.0 & \\
\hline Yes & -17.7 & $(-29.7,-5.7)$ & -17.5 & $(-33.1,-2.0)$ & -19.8 & $(-39.6,0.0)$ & -18.7 & $(-31.9,-5.5)$ \\
\hline \multicolumn{9}{|l|}{ Time since ART initiation } \\
\hline$>6$ to $\leq 12$ months* & 0.0 & & 0.0 & & 0.0 & & 0.0 & \\
\hline$>12$ to $\leq 18$ months & -21.5 & $(-37.8,-5.2)$ & -29.4 & $(-48.2,-10.6)$ & -16.3 & $(-40.9,8.3)$ & -19.6 & $(-37.8,-1.4)$ \\
\hline$>18$ to $\leq 24$ months & -25.8 & $(-42.0,-9.7)$ & -32.8 & $(-51.9,-13.7)$ & -13.9 & $(-38.8,10.9)$ & -25.8 & $(-43.6,-7.9)$ \\
\hline$>24$ or more months & -59.1 & $(-71.7,-46.5)$ & -65.6 & $(-80.7,-50.5)$ & -55.4 & $(-75.3,-35.5)$ & -59.1 & $(-73.1,-45.0)$ \\
\hline Constant & 205.5 & $(174.4,236.6)$ & 207.2 & $(157.7,256.6)$ & 192.8 & $(121.4,264.2)$ & 200.6 & $(166.6,234.6)$ \\
\hline
\end{tabular}

* Difference were compared with the first category of each categorical variable

HIV VL tests, the CD4 count slope was associated with age, concurrent CD4 count and HIV VL, disease stage, hepatitis coinfection and time since cART initiation. After cART initiation, CD4 counts continued to increase even when the concurrent HIV VL was detectable. However, HIV VL needed to be controlled at a lower level to maintain a positive CD4 count slope when cART continues at later stages, particularly from 6 months to more than 24 months after cART initiation.

The inverse relationship between age and CD4 restoration has been reported in previous studies. In these studies younger age was associated with more rapid CD4 recovery and was associated with preserved thymic function [7,13-15]. The increase in CD4 slope after TB diagnosis, compared to CDC category A illness, might seem counterintuitive. This might be simply due to the increased total lymphocytes during active infections. The increase could also be the short-term response due to the increased adherence to cART [16,17] and introduction of treatment for TB or other ADI $[18,19]$.
Studies have shown that neither HBV nor HCV coinfection influence virological response to cART [20-22]. However, in terms of immunological response, the results were mixed [20,21,23-25]. Law et al observed in $\mathrm{HIV}$-infected patients with $\mathrm{HBV}$ or $\mathrm{HCV}$ an initially delayed CD4 count recovery at week four after HAART treatment, but at week 48 the CD4 count increase was similar to the patients only infected with HIV [26]. These studies examine the absolute CD4 count rather than the trend since cART initiation. A decrease in CD4 count slope of less than 20 cells might not be clinically significant in the early phase of cART, but from our estimates (Table 3), it does have a significant impact on whether the CD4 count slope decreased after longer durations of cART. For example, the patient with no hepatitis co-infection would continue to have a CD4 count increase over 20 cells $/ \mu \mathrm{L}$ more than 24 months after cART initiation even the concurrent HIV VL is above 500 copies $/ \mathrm{mL}$. If this patient is co-infected with hepatitis and on cART for more than 24 months, the 
CD4 count slope is below 20 cells $/ \mu \mathrm{L}$ even the concurrent HIV VL is 500 copies $/ \mathrm{mL}$.

The PLATO study [7] reported that in patients experiencing triple class failure, treatment regimens that maintain the VL below 10000 copies $/ \mathrm{mL}$ or at least provide $1.5 \log 10$ copies/mL suppression below the off-treatment value do not seem to be associated with appreciable CD4-cell-count decline. In a combined analysis between Asian and Australian patients infected HIV, Egger et al [14] reported a three-way interaction between the time since cART, baseline CD4 and post-cART HIV VL and estimated that for patients with intermittent HIV viral suppression (below 400 copies $/ \mathrm{mL}$ ), the mean absolute CD4 count begins to decrease or plateau after 4 years of cART. These studies and our findings show that after cART initiation, mean CD4 count slope can continued to increase even when the concurrent HIV VL is detectable. While Egger et al introduced the effect of time in the equation of long term patterns of CD4 response, the results from this analysis further added that the concurrent HIV VL level is a significant factor in determining the trend of CD4 after cART.

Using data from EuroSIDA, Mocroft et al [8] reported that CD4 did not significantly decrease even HIV VL exceeded 10000 copies $/ \mathrm{mL}$ in patients treated with regimen containing a boosted protease inhibitor. Drug class and cART containing abacavir was also included in the analysis, however, none remained significant in the final model. This might be due to three reasons: first, the paper by Mocroft et al analysed data from EuroSIDA where the predominant cART regimen was PIbased (46\% non-boosted, 23\% boosted PI). TAHOD recruits patients from the Asia Pacific region, with NNRTI-based regimen as the most common initial cART $(63 \%, 15 \%$ non-boosted and $20 \%$ boosted PI). In addition, abacavir was not frequently used in TAHOD; second, the patients who received PI- or NNRTI-based cART as initial regimen might be different between EuroSIDA and TAHOD, which could result in a different recovery pattern of the immune system; three, as suggested by Mocroft et al, larger studies with increased power are needed. Nonetheless, our study provided complementary evidence in patients from Asia Pacific region that $\mathrm{CD} 4$ counts continues to increase even when the concurrent HIV VL was detectable.

Similar to other studies [11-13], our data showed a two-phase CD4 count response with a high CD4 count slope in the first six months after treatment initiation followed by a lower slope. The only factor in the final multivariate model (Table 2) that could be modified and had a significant impact on CD4 count slope was the concurrent HIV VL, which is a $40 \mathrm{CD} 4$ cells decrease for every $1 \log 10$ HIV VL increase. From our estimation (Table 3), the CD4 count continues to increase with
HIV VL up to 20000 copies/mL during 6-12 months after cART initiation. However, the HIV VL has to be controlled below 5000,4000 and 500 copies $/ \mathrm{mL}$ for the CD4 count slope to reach a safe level above 20 cells/ $\mu \mathrm{L} /$ year during $12-18,18-24$, and beyond 24 months after cART initiation.

In many countries in Asia, second-line cART is not widely accessible [3-6]. Several studies reported sustainable CD4 count increases in patients with virological failure but remained on the same failing cART [27-29]. Our results suggest that patients with detectable but modest VL may continue their failing CART regimen without increasing their immune deficiency and the risk of poor clinical outcomes over the short term. This is in agreement with the US treatment guideline [2], which recommended adherence assessment, repeated HIV VL tests to rule out "blips" [30], and genotypic tests to detect drug resistant mutations before considering treatment switch. The recent 2009 revision of the WHO antiretroviral therapy guidelines [31] recommended adherence assessment, repeated HIV VL test, and switch only when HIV VL remains more than 5000 copies/ $\mathrm{mL}$. If HIV VL monitoring is available, switch to second-line cART should be done as soon as possible when treatment failure is established. However, in many countries in Asia, especially those developing countries, frequent HIV VL monitoring and genotypic tests are beyond the limited resource for HIV treatment and care [32]. If CD4 count is the only way for monitoring treatment response, the result of this analysis showed that a patient can have a considerable duration of virological failure without meeting $\mathrm{CD} 4$ criteria recommended by WHO for switch of ART to second line. In addition, the effect of delaying switching treatment on longer term outcomes through the possible development of HIVdrug resistance that could compromise the efficacy of later CART regimens remains uncertain.

\section{Limitations}

Several limitations should be considered in interpreting the results in this paper. First, TAHOD participating sites are generally urban referral centres, and each site recruits 200-300 patients who are considered by local clinicians to have a reasonably good prospect of longterm follow-up. Hence TAHOD patients, and their treatment, are not representative of all HIV-infected patients in the Asia and Pacific region. Second, we do not have data on adherence and treatment against $\mathrm{TB}$ and other ADI. Finally, a more thorough analysis would include the survival outcome. However, because of the limited number and follow-up of patients who were failing virologically, this analysis is currently underpowered. Further analyses will be considered with longer duration of follow-up. 


\section{Conclusion}

The analyses suggest that after cART initiation, mean CD4 slope can continue to increase even when the concurrent HIV VL is detectable. HIV VL needed to be controlled at a lower level to maintain a positive CD4 slope beyond 2 years of cART. However, the effect on longer term outcomes through the possible development of HIV-drug resistance remains uncertain.

\section{Acknowledgements}

The TREAT Asia HIV Observational Database is part of the Asia Pacific HIV Observational Database and is an initiative of TREAT Asia, a program of amfAR, The Foundation for AIDS Research, with support from the National Institute of Allergy and Infectious Diseases (NIAID) of the U.S. National Institutes of Health $(\mathrm{NIH})$ as part of the International Epidemiologic Databases to Evaluate AIDS (leDEA) (grant no. U01Al069907), and from the Dutch Ministry of Foreign Affairs through a partnership with Stichting Aids Fonds. The National Centre in HIV Epidemiology and Clinical Research is funded by the Australian Government Department of Health and Ageing, and is affiliated with the Faculty of Medicine, The University of New South Wales. The content of this publication is solely the responsibility of the authors and does not necessarily represent the official views of any of the institutions mentioned above.

\section{The TREAT Asia HIV Observational Database}

CV Mean, V Saphonn* and K Vohith, National Center for HIV/AIDS, Dermatology \& STDs, Phnom Penh, Cambodia;

FJ Zhang*, HX Zhao and N Han, Beijing Ditan Hospital, Beijing, China; PCK Li* and MP Lee, Queen Elizabeth Hospital, Hong Kong, China;

N Kumarasamy* and S Saghayam, YRG Centre for AIDS Research and Education, Chennai, India;

S Pujari* ${ }^{*}$ and K Joshi, Institute of Infectious Diseases, Pune, India; TP Merati* and F Yuliana, Faculty of Medicine Udayana University \& Sanglah Hospital, Bali, Indonesia;

E Yunihastuti* and O Ramadian, Working Group on AIDS Faculty of Medicine, University of Indonesia/Ciptomangunkusumo Hospital, Jakarta, Indonesia;

S Oka* and M Honda, International Medical Centre of Japan, Tokyo, Japan; JY Choi* and SH Han, Division of Infectious Diseases, Dept. of Internal Medicine, Yonsei University College of Medicine, Seoul, South Korea; C KC Lee* and R David, Hospital Sungai Buloh, Kuala Lumpur, Malaysia; A Kamarulzaman* and A Kajindran, University of Malaya Medical Centre, Kuala Lumpur, Malaysia;

G Tau, Port Moresby General Hospital, Port Moresby, Papua New Guinea**; R Ditangco* and R Capistrano, Research Institute for Tropical Medicine, Manila, Philippines;

YMA Chen*, WW Wong and YW Yang, Taipei Veterans General Hospital and AIDS Prevention and Research Centre, National Yang-Ming University, Taipei, Taiwan;

PL Lim*, OT Ng and E Foo, Tan Tock Seng Hospital, Singapore; P Phanuphak*, and M Khongphattanayothin, HIV-NAT/Thai Red Cross AIDS Research Centre, Bangkok, Thailand;

S Sungkanuparph*, S Kiertiburanakul, and B Piyavong, Faculty of Medicine Ramathibodi Hospital, Mahidol University, Bangkok, Thailand;

T Sirisanthana* + and W Kotarathititum, Research Institute for Health Sciences, Chiang Mai, Thailand;

J Chuah*, Gold Coast Sexual Health Clinic, Miami, Queensland, Australia; AH Sohn*, L Messerschmidt* and B Petersen, TREAT Asia, amfAR - The Foundation for AIDS Research, Bangkok, Thailand;

DA Cooper, MG Law*, J Zhou* and A Jiamsakul, National Centre in HIV Epidemiology and Clinical Research, The University of New South Wales, Sydney, Australia.

* TAHOD Steering Committee member; ${ }^{* *}$ Inactive site; $†$ Steering Committee Chair; $\neq$ co-Chair.

\section{Author details}

${ }^{1}$ National Centre in HIV Epidemiology and Clinical Research, The University of New South Wales, Sydney, Australia. ${ }^{2}$ Research Institute for Health
Sciences, Chiang Mai University, Chiang Mai, Thailand. ${ }^{3}$ Faculty of Medicine Ramathibodi Hospital, Mahidol University, Bangkok, Thailand. ${ }^{4}$ Taipei Veterans General Hospital and AIDS Prevention and Research Centre, National YangMing University, Taipei, Taiwan. ${ }^{5}$ Beijing Ditan Hospital, Beijing, China. ${ }^{6}$ Tan Tock Seng Hospital, Singapore. ${ }^{7}$ YRG Centre for AIDS Research and Education, Chennai, India. ${ }^{8}$ Department of Internal Medicine and AIDS Research Institute, Yonsei University College of Medicine, Seoul, Korea. ${ }^{9}$ School of Medicine Udayana University \& Sanglah Hospital, Denpasar, Bali, Indonesia. ${ }^{10}$ Working Group on AIDS Faculty of Medicine, University of Indonesia/Ciptomangunkusumo Hospital, Jakarta, Indonesia. ${ }^{11}$ International Medical Centre of Japan, Tokyo, Japan. ${ }^{12}$ University of Malaya Medical Centre, Kuala Lumpur, Malaysia. ${ }^{13}$ HIV-NAT/Thai Red Cross AIDS Research Centre, Bangkok, Thailand. ${ }^{14}$ Hospital Sungai Buloh, Kuala Lumpur, Malaysia. ${ }^{15}$ Queen Elizabeth Hospital, Hong Kong, China. ${ }^{16}$ Institute of Infectious Diseases, Pune, India. ${ }^{17}$ National Center for HIV/AIDS, Dermatology \& STDs, Phnom Penh, Cambodia.

\section{Authors' contributions}

$\mathrm{JZ}$ and ML originated the study concept and detailed the analysis plan. JZ performed the data manipulation, statistical analysis, interpretation of results and drafted the manuscript. TS, SK, YMC, NH, PLL, NK, JYC, TPT and EY commented on the study concept and analysis plan, helped interpretation of results and edited the manuscript. SO, AK, PP, CL, PL, VS reviewed the manuscript and provided clinical interpretations. All authors read and approved the final manuscript.

\section{Competing interests}

The authors declare that they have no competing interests.

Received: 19 September 2010 Accepted: 23 December 2010 Published: 23 December 2010

\section{References}

1. Finzi D, Blankson J, Siliciano JD, Margolick JB, Chadwick K, Pierson T, Smith K, Lisziewicz J, Lori F, Flexner C, Quinn TC, Chaisson RE, Rosenberg E, Walker B, Gange S, Gallant J, Siliciano RF: Latent infection of CD4+ T cells provides a mechanism for lifelong persistence of HIV-1, even in patients on effective combination therapy. Nat Med 1999, 5(5):512-517.

2. Guidelines for the Use of Antiretroviral Agents in HIV-1-Infected Adults and Adolescents. [http://www.aidsinfo.nih.gov/ContentFiles/ AdultandAdolescentGL.pdf], Accessed Oct 2010.

3. WHO, UNAIDS, UNICEF: Towards universal access: scaling up priority HIV/ AIDS interventions in the health sector. Progress report 2009. Geneva 2009.

4. Hogan DR, Salomon JA: Prevention and treatment of human immunodeficiency virus/acquired immunodeficiency syndrome in resource-limited settings. Bull World Health Organ 2005, 83(2):135-143.

5. Boyd MA, Cooper DA: Second-line combination antiretroviral therapy in resource-limited settings: facing the challenges through clinical research. AIDS 2007, 21(Suppl 4):S55-63.

6. Zhou J, Li P, Kumarasamy N, Boyd M, Chen Y, Sirisanthana T, Sungkanuparph S, Oka S, Tau G, Phanuphak P, Saphonn V, Zhang F, Omar S, Lee C, Ditangco R, Merati T, Lim P, Choi J, Law M, Pujari S: Deferred modification of antiretroviral regimen following documented treatment failure in Asia: results from the TREAT Asia HIV Observational Database (TAHOD). HIV Med 2009, 11(1):31-39.

7. Ledergerber B, Lundgren JD, Walker AS, Sabin C, Justice A, Reiss P, Mussini C, Wit F, d'Arminio Monforte A, Weber R, Fusco G, Staszewski S, Law M, Hogg R, Lampe F, Gill MJ, Castelli F, Phillips AN: Predictors of trend in CD4-positive T-cell count and mortality among HIV-1-infected individuals with virological failure to all three antiretroviral-drug classes. Lancet 2004, 364(9428):51-62.

8. Mocroft A, Phillips AN, Ledergerber B, Smith C, Bogner JR, Lacombe K, Wiercinska-Drapalo A, Reiss P, Kirk O, Lundgren JD: Estimated average annual rate of change of CD4(+) T-cell counts in patients on combination antiretroviral therapy. Antivir Ther 2010, 15(4):563-570.

9. Boyd M, Emery S, Cooper DA: Antiretroviral roll-out: the problem of second-line therapy. Lancet 2009, 374(9685):185-186.

10. Zhou J, Kumarasamy N, Ditangco R, Kamarulzaman A, Lee CK, Li PC, Paton NI, Phanuphak P, Pujari S, Vibhagool A, Wong WW, Zhang F, Chuah J, Frost KR, Cooper DA, Law MG: The TREAT Asia HIV Observational 
Database: Baseline and Retrospective Data. J Acquir Immune Defic Syndr 2005, 38(2):174-179.

11. Kaufmann GR, Zaunders JJ, Cunningham P, Kelleher AD, Grey P, Smith D, Carr A, Cooper DA: Rapid restoration of CD4 T cell subsets in subjects receiving antiretroviral therapy during primary HIV-1 infection. AIDS 2000, 14(17):2643-2651.

12. Kaufmann GR, Perrin L, Pantaleo G, Opravil M, Furrer H, Telenti A, Hirschel B, Ledergerber B, Vernazza P, Bernasconi E, Rickenbach M, Egger M, Battegay M: CD4 T-lymphocyte recovery in individuals with advanced HIV-1 infection receiving potent antiretroviral therapy for 4 years: the Swiss HIV Cohort Study. Arch Intern Med 2003, 163(18):2187-2195.

13. Moore RD, Keruly JC: CD4+ cell count 6 years after commencement of highly active antiretroviral therapy in persons with sustained virologic suppression. Clin Infect Dis 2007, 44(3):441-446.

14. Egger S, Petoumenos K, Kamarulzaman A, Hoy J, Sungkanuparph S, Chuah J, Falster K, Zhou J, Law MG: Long-term patterns in CD4 response are determined by an interaction between baseline CD4 cell count, viral load, and time: The Asia Pacific HIV Observational Database (APHOD). J Acquir Immune Defic Syndr 2009, 50(5):513-520.

15. Viard JP, Mocroft A, Chiesi A, Kirk O, Roge B, Panos G, Vetter N, Bruun JN, Johnson $\mathrm{M}$, Lundgren JD: Influence of age on CD4 cell recovery in human immunodeficiency virus-infected patients receiving highly active antiretroviral therapy: evidence from the EuroSIDA study. $J$ Infect Dis 2001, 183(8):1290-1294.

16. Parsons JT, Golub SA, Rosof E, Holder C: Motivational interviewing and cognitive-behavioral intervention to improve HIV medication adherence among hazardous drinkers: a randomized controlled trial. J Acquir Immune Defic Syndr 2007, 46(4):443-450.

17. Simoni JM, Huh D, Frick PA, Pearson CR, Andrasik MP, Dunbar PJ, Hooton TM: Peer support and pager messaging to promote antiretroviral modifying therapy in Seattle: a randomized controlled trial. J Acquir Immune Defic Syndr 2009, 52(4):465-473.

18. Martin DJ, Sim JG, Sole GJ, Rymer L, Shalekoff S, van Niekerk AB, Becker $P$, Weilbach CN, Iwanik J, Keddy K, et al: CD4+ lymphocyte count in African patients co-infected with HIV and tuberculosis. J Acquir Immune Defic Syndr Hum Retrovirol 1995, 8(4):386-391.

19. Morris L, Martin DJ, Bredell H, Nyoka SN, Sacks L, Pendle S, Page-Shipp L, Karp CL, Sterling TR, Quinn TC, Chaisson RE: Human immunodeficiency virus-1 RNA levels and CD4 lymphocyte counts, during treatment for active tuberculosis, in South African patients. J Infect Dis 2003, 187(12):1967-1971.

20. De Luca A, Bugarini R, Lepri AC, Puoti M, Girardi E, Antinori A, Poggio A, Pagano G, Tositti G, Cadeo G, Macor A, Toti M, D'Arminio Monforte A: Coinfection with hepatitis viruses and outcome of initial antiretroviral regimens in previously naive HIV-infected subjects. Arch Intern Med 2002, 162(18):2125-2132.

21. Rockstroh JK, Mocroft A, Soriano V, Tural C, Losso MH, Horban A, Kirk O, Phillips A, Ledergerber B, Lundgren J: Influence of hepatitis C virus infection on HIV-1 disease progression and response to highly active antiretroviral therapy. J Infect Dis 2005, 192(6):992-1002.

22. Zhou J, Dore GJ, Zhang F, Lim PL, Chen YM: Hepatitis B and C virus coinfection in The TREAT Asia HIV Observational Database. J Gastroenterol Hepatol 2007, 22(9):1510-1518.

23. Greub $G$, Ledergerber $B$, Battegay $M, G$ Grob $P$, Perrin $L$, Furrer $H$, Burgisser $P$, Erb P, Boggian K, Piffaretti JC, Hirschel B, Janin P, Francioli P, Flepp M, Telenti A: Clinical progression, survival, and immune recovery during antiretroviral therapy in patients with HIV-1 and hepatitis $C$ virus coinfection: the Swiss HIV Cohort Study. Lancet 2000, 356(9244):1800-1805.

24. Sulkowski MS, Moore RD, Mehta SH, Chaisson RE, Thomas DL: Hepatitis C and progression of HIV disease. Jama 2002, 288(2):199-206.

25. Konopnicki D, Mocroft A, de Wit S, Antunes F, Ledergerber B, Katlama C, Zilmer K, Vella S, Kirk O, Lundgren JD: Hepatitis B and HIV: prevalence, AIDS progression, response to highly active antiretroviral therapy and increased mortality in the EuroSIDA cohort. AIDS 2005, 19(6):593-601.

26. Law WP, Duncombe CJ, Mahanontharit A, Boyd MA, Ruxrungtham K, Lange JM, Phanuphak P, Cooper DA, Dore GJ: Impact of viral hepatitis coinfection on response to antiretroviral therapy and HIV disease progression in the HIV-NAT cohort. AIDS 2004, 18(8):1169-1177.

27. Staszewski S, Miller V, Sabin C, Schlecht C, Gute P, Stamm S, Leder T, Berger A, Weidemann E, Hill A, Phillips A: Determinants of sustainable CD4 lymphocyte count increases in response to antiretroviral therapy. AIDS 1999, 13(8):951-956.

28. Deeks SG, Barbour JD, Grant RM, Martin JN: Duration and predictors of CD4 T-cell gains in patients who continue combination therapy despite detectable plasma viremia. AIDS 2002, 16(2):201-207.

29. Cozzi-Lepri A, Phillips AN, Miller V, Katlama C, Ledergerber B, Vella S, Weber J, Bruun JN, Kirk O, Clotet B, Lundgrens JD: Changes in viral load in people with virological failure who remain on the same HAART regimen. Antivir Ther 2003, 8(2):127-136.

30. Nettles RE, Kieffer TL, Kwon P, Monie D, Han Y, Parsons T, Cofrancesco J, Gallant JE, Quinn TC, Jackson B, Flexner C, Carson K, Ray S, Persaud D, Siliciano RF: Intermittent HIV-1 viremia (Blips) and drug resistance in patients receiving HAART. JAMA 2005, 293(7):817-829.

31. WHO: Antiretroviral therapy for HIV infection in adults and adolescents. Recommendations for a public health approach. 2009 revision. Geneva 2010.

32. Oyomopito R, Lee MP, Phanuphak P, Lim PL, Ditangco R, Zhou J, Sirisanthana T, Chen YM, Pujari S, Kumarasamy N, Sungkanuparph S, Lee CK, Kamarulzaman A, Oka S, Zhang FJ, Mean CV, Merati T, Tau G, Smith J, Li PC: Measures of site resourcing predict virologic suppression, immunologic response and HIV disease progression following highly active antiretroviral therapy (HAART) in the TREAT Asia HIV Observational Database (TAHOD). HIV Med 2010, 11(8):519-529.

\section{Pre-publication history}

The pre-publication history for this paper can be accessed here: http://www.biomedcentral.com/1471-2334/10/361/prepub

doi:10.1186/1471-2334-10-361

Cite this article as: Zhou et al.: Trends in CD4 counts in HIV-infected patients with HIV viral load monitoring while on combination antiretroviral treatment: results from The TREAT Asia HIV Observational Database. BMC Infectious Diseases 2010 10:361.

\section{Submit your next manuscript to BioMed Central and take full advantage of:}

- Convenient online submission

- Thorough peer review

- No space constraints or color figure charges

- Immediate publication on acceptance

- Inclusion in PubMed, CAS, Scopus and Google Scholar

- Research which is freely available for redistribution

Submit your manuscript at www.biomedcentral.com/submit
C Biomed Central 